\title{
ROLE OF MULTI-SLICE SPIRAL CT IN THE EVALUATION OF NECK MASS WITH CYTOLOGICAL CORRELATION
}

\section{Das Runa, Ghosh Aniruddha}

${ }^{1}$ Associate Professor, ${ }^{2}$ Senior Resident, Department of Radio Diagnosis, Burdwan Medical College, Baburbag, Rajbati Bundwan, West Bengal, India

\section{ABSTRACT}

Abstract: The swellings in the neck can be caused by innumerable pathological lesions arising from the various anatomical structures lying therein. Multi-Detector CT (MDCT) has now become the new standard in a radiological imaging modality. The utilization of MDCT has resulted in improved resolution and considerable reductions in scan acquisition and display time. Aim and Objective: This study is an effort to assess the role of MDCT in detection, characterization and diagnosing neck pathologies that correlate cytologically. Methods: A study of 50 cases in a clinically suspected neck mass was studied. Contrast-enhanced CT neck was done, and Specific CT criteria were used to characterize the mass so that a probable diagnosis could be made. MDCT diagnoses then compared with cytological results to conclude efficiency of MDCT analysis of neck mass. Results: In our study, the correlation between MDCT diagnosis and pathological diagnosis was significant $(\mathrm{p}<0.001)$ when we compare both the modalities for diagnosing malignancy. The sensitivity, specificity, positive predictive value, negative predictive value and accuracy is $92.3 \%, 87.5 \%$, $88.9 \%, 91.3 \%, 90 \%$ respectively. Conclusion: Multi-detector computed tomography helps in precise anatomical localization and characterization of neck masses. Hence, it will be a method of choice for initial evaluation, preoperative planning, and biopsy targeting and postoperative follow-up.

Keywords: Neck mass; Cervical lymph node; Computed tomography; Carcinoma

\section{INTRODUCTION}

The neck is a wide anatomical area, and a detailed understanding of neck anatomy is critical to reaching a differential diagnosis [1]. It encompasses a wide variety of anatomical structures that belong to different organ systems, and thus the swellings in the neck can be caused by innumerable pathological lesions arising from the various anatomical structures lying therein [2]. In addition to metastases from malignancies commonly are neck masses, cervical lymphadenopathy is one of the common causes of neck masses in our country due to the prevalence of tuberculosis [3].

Clinical history and examination are usually the first step in the diagnostic evaluation of such masses and help in the gross differentiation of such masses. MultiDetector CT (MDCT) has now become the new standard in a radiological imaging modality. The utilization of MDCT has resulted in improved resolution and considerable reductions in scan acquisition and display time [4]. This study is an effort to assess the role of MDCT in detection, characterization and diagnosing neck pathologies, which may help in deciding further course of management, and findings will be correlated cytologically.

\section{MATERIAL AND METHODOLOGY}

Study design: The study was a hospital-based, crosssectional descriptive study

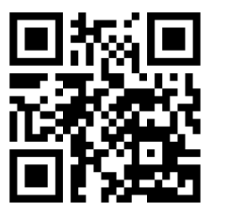

DOI: $10.31878 / \mathrm{ijcbr} .2019 .61 .04$

eISSN: 2395-0471

pISSN: 2521-0394
Ethical approval and informed consent: Ethical approval granted by the college Ethics Committee. Patients were incorporated into this study after taking proper consent.

Study location: Study was conducted at the Department of Radiodiagnosis, Burdwan Medical College

Study time frame: July 2017 to June 2018

Study population: fifty patients irrespective of age and sex presenting with neck mass studied over the period of one year after fulfilling inclusion criteria.

\section{Exclusion criteria:}

We have tried to reach a definite diagnosis utilizing the available clinical, radiological \& cytological data. Each patient of our study was subjected to thorough clinical examination and radiological evaluation. Specific CT criteria were used to characterize the mass so that a probable diagnosis could be made. USG guided FNAC then performed aseptically and later on, and the cytological analysis was carried away. MDCT diagnoses then compared with cytological results to conclude the efficiency of MDCT analysis of neck mass.

Statistical analysis: Data was analysed and diagnostic accuracy, sensitivity, specificity of MDCT is assessed

\section{RESULTS}

In the present study, male preponderance was noted that is, $52 \%$ of the patients were males compared to $48 \%$ females with male to female ratio of 1.08:1

The patients' age ranges from 7 year to 76 years, with a mean age of 42.46 .

Correspondence: Ghosh Aniruddha, Department of Radio Diagnosis, Burdwan Medical College, Baburbag, Rajbati Bundwan, West Bengal, India ani.gogol123@gmail.com 
Table 1: Distribution of cases based on age

\begin{tabular}{cc}
\hline AGE ( years) & Distribution $\{\mathbf{n}(\%\}$ \\
\hline$<10$ & $3(6)$ \\
$21-20$ & $3(6)$ \\
$31-40$ & $7(14)$ \\
$41-50$ & $9(18)$ \\
$51-60$ & $10(20)$ \\
$61-70$ & $10(20)$ \\
$>71$ & $5(10)$ \\
\hline
\end{tabular}

Table 2: Distribution neck masses into benign, malignant groups according to MDCT characters

\begin{tabular}{|c|c|c|}
\hline & MDCT DIAGNOSIS & $\mathbf{N}$ \\
\hline \multirow{3}{*}{$\begin{array}{l}\text { Benign } \\
\text { lesions } \\
\{n=23 \\
(46 \%)\}\end{array}$} & Thyroid & 5 \\
\hline & Thyroglossal cyst & 1 \\
\hline & Parotid (Salivary adenoma) & 2 \\
\hline \multirow{17}{*}{ 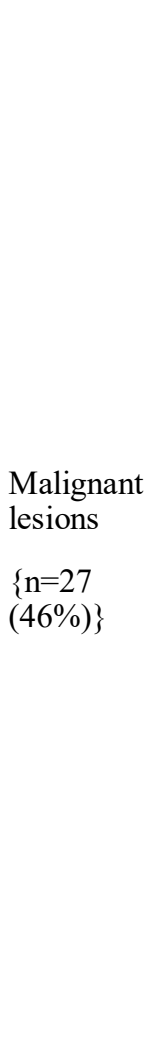 } & Localized abscess & 2 \\
\hline & Schwannoma & 2 \\
\hline & TB Lymphadenitis & 6 \\
\hline & Reactive lymph node & 2 \\
\hline & Lipoma & 1 \\
\hline & Inflammatory lateral neck mass & 1 \\
\hline & $\begin{array}{l}\text { Inflammatory mass in masticator } \\
\text { space }\end{array}$ & 1 \\
\hline & Buccal carcinoma & 6 \\
\hline & Tongue carcinoma & 5 \\
\hline & Thyroid carcinoma & 5 \\
\hline & Pyriform sinus carcinoma & 2 \\
\hline & Carcinoma larynx & 3 \\
\hline & Carcinoma mandible & 1 \\
\hline & Esophageal carcinoma & 1 \\
\hline & Carcinoma oropharynx & 1 \\
\hline & Lymphoma & 2 \\
\hline & Carcinoma alveolar process & 1 \\
\hline
\end{tabular}

In the present study's most common presenting complaint was that of neck mass, which was seen in 48 $(96 \%)$ patients a were mainly due to cervical lymphadenopathy, which was an associated complaint with the primary site of malignancy. The second most frequent presenting complaint was that of painless ulcers seen in 21 cases $(24 \%)$ of patients.

Of the lesions involving the suprahyoid neck spaces, the maximum number of lesions were recorded in the buccal space $(n=6)$ majority of which were found to be squamous cell carcinoma. In the infrahyoid neck, the predominant lesions $(n=17)$ were observed in the visceral space. Thyroid origin lesions constitute the bulk of the visceral space lesions. The distribution of neck mass into benign and malignant groups according to MDCT characters shown in table 2 .

32 patients out of 50 present with cervical lymphadenopathy. The majority of $(n=22)$ were due to metastatic secondary with a known primary in the head-neck region. Two cases of lymphoma and six cases of tubercular lymphadenitis were also diagnosed.

The CT criteria used to characterize the lesions were margins, enhancement pattern, necrosis, surrounding soft tissue infiltration, bone erosion, vascular invasion and the extent to adjacent neck space. And the findings are tabulated in Table 3

Table 3: Distribution of various $\mathrm{CT}$ characters in between malignant and benign lesions

\begin{tabular}{lccc}
\hline Character & $\begin{array}{l}\text { Malignant } \\
\text { n (\%) }\end{array}$ & $\begin{array}{l}\text { Benign } \\
\text { n (\%) }\end{array}$ & $\begin{array}{l}\text { Total } \\
\text { n (\%) }\end{array}$ \\
\hline $\begin{array}{l}\text { Heterogenous } \\
\text { enhancement }\end{array}$ & $24(92.3)$ & $18(75)$ & $42(84)$ \\
$\begin{array}{l}\text { Irregular marzine } \\
\text { Necrosis }\end{array}$ & $14(53.8)$ & $13(54)$ & $27(54)$ \\
$\begin{array}{l}\text { Soft tissue infil- } \\
\text { tration }\end{array}$ & $23(88.5)$ & $6(25)$ & $29(58)$ \\
$\begin{array}{l}\text { Bone erosion } \\
\begin{array}{l}\text { Vascular inva- } \\
\text { sion }\end{array}\end{array}$ & $2(23.1)$ & 0 & $6(12)$ \\
$\begin{array}{l}\text { Extent to adja- } \\
\text { cent space }\end{array}$ & $4(15.4)$ & $4(16.7)$ & $8(16)$ \\
\hline
\end{tabular}

Twenty-seven lesions were diagnosed on CT as malignant. There were three cases that were diagnosed as malignant lesion two was the malignant transformation of adenomatous goiter and one was tongue carcinoma, which on pathological test turned out to be adenomatous goiter and chronic cell infiltrate. Of the 23 cases identified as benign, 21 turned out to be benign while two were malignant lesions on histopathology.

There were two cases which were diagnosed as a chronic inflammatory lesion of masticator space and one was inflammatory pseudotumor they were diagnosed as undifferentiated sarcoma and round cell tumor respectively on histopathology.

The diagnoses of CT have been compared with the histopathology diagnoses in Table 4 . The sensitivity of CT in detecting malignant/benign lesions was $92.3 \%$ with a specificity of $87.5 \%$, the positive predictive value of 88.9 $\%$ and a negative predictive value of $91.3 \%$ and accuracy $90 \%$ (Table 4). 
Table 4: CT and Pathological Correlation of Benign Vs Malignant Lesions

\begin{tabular}{llcc}
\hline & & \multicolumn{2}{c}{ Pathological diagnosis } \\
\cline { 3 - 4 } & & Malignant & Benign \\
CT & Malignant & 24 & 3 \\
diagnosis & Benign & 2 & 21 \\
& & & \\
\hline
\end{tabular}

Sensitivity $=92.3 \%$, Specificity $=87.5 \%$, Positive predictive value $=88.9 \% \quad$ Negative predictive value $=$ $91.3 \%$

\section{DISCUSSION}

In the present study most, the common presenting complaint was that of neck mass, which was seen in 48 $(96 \%)$ patients who were mainly due to cervical lymphadenopathy, which was an associated complaint with the primary site of malignancy. The second most frequent presenting complaint was that of painless ulcer seen in 21 cases $(24 \%)$ of patients, were mostly seen in gingivobuccal and tongue cancers. Dobrossy L [5] did a study in the year 2005 in which the oral cavity was the most common site of lesion seen in $40 \%$ of patients and presented with complaints of non-healing oral ulcers

In the present study, $34 \%$ of the patients had visceral neck space involvement, which included pyriform sinus, larynx, thyroid and esophageal in the present study. A similar finding was noted in a study done by Mathur R [6] in the year 2016 .

Our heterogeneous study enhancement was noted in 42 out of 50 primary lesions

characterized by a CT scan. Ill-defined margins in 32 out of 50 patients. Lymph nodes metastasis was seen in 22 out of 24 primary malignant lesions. Infiltration of surrounding soft tissue was seen in 29 out of 50 cases. Bone erosion and vascular invasion noted in 6 and 2 cases respectively

Heterogenous enhancement found in $92.3 \%$ of malignant lesions. Similarly, irregular margin and soft tissue infiltration noted in $92.3 \%$ and $88.46 \%$ of malignancy, respectively. Heterogenous enhancement and necrosis also noted in some benign lesions. Bone erosion found to be a highly specific feature for malignancy. CT features like irregular margin, surrounding soft tissue infiltration, etc were found to be statistically significant in differentiating malignant and benign lesions. Kurabayashi $\mathrm{T}$ [7] in their study found 11 malignant lesions out of 53 with a sensitivity of $64 \%$ on the bases of margins, internal architecture and adjacent plane invasion on CT scan.

In our study, the correlation between MDCT diagnosis and pathological diagnosis was significant $(\mathrm{p}<0.001)$ when we compare both the modalities for diagnosing malignancy. The sensitivity, specificity, positive predictive value, negative predictive value and accuracy is $92.3 \%, 87.5 \%, 88.9 \%, 91.3 \%, 90 \%$ respectively. Mathur $\mathrm{R}$ [6] et al., in their study, mentioned a similar finding in CT differentiating benign and malignant lesions with a sensitivity of $96 \%$ and specificity and accuracy of $93 \%$. Liao LJ [8] did a meta-analytic review of various studies and made a pooled estimate in which sensitivity was
$52 \%$, and specificity was $93 \%$ for MDCT detecting malignant lesion.

\section{CONCLUSION}

Multi-detector computed tomography helps in precise anatomical localization and characterization of neck masses. Hence, it will be a method of choice for initial evaluation, preoperative planning, and biopsy targeting and postoperative follow-up.

Limitations: The current study included all neck mass lesions, irrespective of their diagnosis and histopathological variety. It would have been better if an individual type of lesion could be considered separately. A large -scale study with great logistic support and adequate randomization is thus recommended.

Clinical uses: Accurate delineation of pathologies by MDCT provides a reliable preoperative diagnosis, helps in staging, aspiration cytology, planning of biopsy and post-treatment follow up. Hence, Multidetector CT is currently one of the most versatile and powerful imaging procedures for the initial evaluation of neck masses.

Conflict of interest : Nil

Source of funding : Nil

\section{REFERENCES}

[1] Harnsberger HR. Parapharyngeal space overview. In: Harnsberger HR, editor. Diagnostic imaging: head and neck. Altona (Canada): Amirsys; 2011

[2] Jindal U, Singh K, Baghla A, Kochhar A. Spectrum of Neck Swellings in the rural population Of India Based On Fine Needle Aspiration Findings. IJHNS. 2012; 5(2):1-6.

[3] Prasad KC, Sreedharan S, Chakravarthy Y, Prasad SC. Tuberculosis in the head and neck: experience in India. The Journal of Laryngology \& Otology. 2007 Oct;121(10):979-85.

[4] Gupta P, Bhargava SK, Mehrotra G, Rathi V. Role of multi-slice spiral CT in the evaluation of neck masses. Journal International Medical Sciences Academy. 2013; 26(1):51-4.

[5] Döbróssy L. Epidemiology of neck cancer: magnitude of the problem. Cancer and Metastasis Reviews. $2005 ; 24(1): 9-17$.

[6] Mathur R, Gupta A, Repswal R. Role of multidetector CT in evaluation of neck lesions. Journal of Evidence based medicine and healthcare 2016; 50 (3):2566-63.

[7] Kurabayashi T, Ida M, Yoshino N, Sasaki T, Kishi T, Kusama M. Computed tomography in the diagnosis of buccal space masses.Dentomaxillofacial Radiology. 1997; 26(6):347-53

[8] Liao LJ, Lo WC, Hsu WL. Detection of cervical lymph node metastasis in neck cancer patients with clinically N0 neck-a metaanalysis comparing different imaging modalities. BMC cancer. 2012;12(1):236 